\title{
Distribution des médicaments
}

santésuisse

Monsieur Ch. Brändli

Monsieur M.-A. Giger

Römerstrasse 20

4502 Soleure

Berne, le 2 avril 2002 HHB/dr/fxd

Messieurs,

La Fédération des médecins suisses (FMH) a pris connaissance de vos données chiffrées ayant trait à l'augmentation des volumes et des coûts dans le canal de la distribution des médicaments par les médecins. Les chiffres que vous avez publiés, dans l'état de nos connaissances, ne sont ni compréhensibles ni plausibles. Nous attendons de votre part une présentation ouverte de ces données chiffrées afin de rendre compréhensibles les déclarations que vous en inférez. Sur la base de cette analyse, nous publierons une prise de position dans le Bulletin des médecins suisses.
Nous allons nous mettre sans délai en contact avec vous pour convenir d'une rencontre; y participeront du côté de la FMH MM. les Drs Giger, Gehler et Häuptli. Nous partons de l'idée que vous manifestez autant d'intérêt que nousmêmes à une clarification aussi rapide que possible de la situation; vous conviendrez sans doute avec nous qu'il est impensable de songer à une introduction en bonne intelligence des tarifs TARMED dans un climat à ce point empoisonné. Veuillez croire, Messieurs, à l'expression de notre parfaite considération.

\section{FMH}

Pour le Comité central

Dr H. H. Brunner

Président

\section{Copies}

- Comité central FMH;

- Sociétés cantonales de médecine;

- Sociétés de discipline médicale;

- Conseil d'administration santésuisse;

- Monsieur M. Manser, Helsana;

- Madame la conseillère fédérale R. Dreifuss, cheffe du DFI;

- Office fédéral des assurances sociales;

- Commission des tarifs médicaux. 